\title{
USP Update: USP Revises the New General Chapter $<3>$ Topical and Transdermal Drug Products: Quality Tests
}

Margareth Marques

USP, Rockville, MD USA
SP is publishing a revision to the proposed General Chapter $<3>$ Topical and Transdermal Drug

Products: Quality Tests in Pharmacopeial Forum (PF), 36 (6), Nov-Dec 2010. This new general chapter was introduced in PF 35 (3), May-June 2009, and the revision is based on the comments received during the public comments period and at the workshop held at the USP headquarters in Rockville, Maryland, in September 2009. The revised text is available at http://www.usp.org/USPNF/ compendialNotices/revisionGC3TopicalTransdermal.html.

This general chapter covers physicochemical tests such as apparent viscosity and uniformity in containers for semisolid topical dosage forms (ointments, gels, creams, lotions, etc.). The adhesion, peel adhesion, release liner peel, probe tack, and leak tests were included for transdermal systems (patches).

Tests to assess drug product performance (in vitro drug substance release) will be included in a new General Chapter <1724> Topical and Transdermal Drug Products: Performance Tests, which will be published in a future issue of PF in 2011.

The deadline to send comments and suggestions to Dr. Margareth Marques at MRM@usp.org is February 15, 2011.

A special announcement is that $P F$ is going to be available free of charge in the USP web site starting Jan 2011. More information is available at http://www.usp.org/USPNF/pf/pfRedesign.html. 